\title{
Ovarian Serous Cystadenoma
}

National Cancer Institute

\section{Source}

National Cancer Institute. Ovarian Serous Cystadenoma. NCI Thesaurus. Code C4511.

A benign, usually bilateral neoplasm of the ovary characterized by the presence of cystic structures that contain watery fluid and are lined by serous epithelial cells. Signs and symptoms include abdominal enlargement, pain, and vaginal bleeding. 